\title{
Early-onset symptomatic neonatal COVID-19 infection with high probability of vertical transmission
}

\author{
Rajesh Kulkarni ${ }^{1} \cdot$ Uday Rajput $^{1} \cdot$ Rahul Dawre $^{1} \cdot$ Chhaya Valvi $^{1} \cdot$ Rema Nagpal $^{1} \cdot$ Nikita Magdum $^{1} \cdot$ Harshali Vankar $^{1}$. \\ Naresh Sonkawade ${ }^{1}$. Aiswarya Das ${ }^{1} \cdot$ Sagar Vartak $^{1}$. Suvarna Joshi ${ }^{2}$. Santosh Varma ${ }^{3}$. Rajesh Karyakarte ${ }^{2}$. \\ Ramesh Bhosale ${ }^{4}$. Aarti Kinikar ${ }^{1}$
}

Received: 18 July 2020 / Accepted: 26 July 2020 / Published online: 2 August 2020

(c) Springer-Verlag GmbH Germany, part of Springer Nature 2020

\begin{abstract}
Background There are few reports of COVID-19 in neonates and most are suspected to be due to postnatal transmission. Vertical transmission has been proven in only a couple of cases so far.

Methods We describe early—onset, severe COVID-19 disease in a neonate with very strong evidence of vertical transmission of SARS-CoV-2.

Results A COVID-19 suspected mother, who tested negative by RT-PCR for COVID, but tested positive for SARS-CoV-2 by serology, delivered a term baby. The neonate was kept in strict isolation. Molecular tests for SARS-CoV-2 on umbilical stump, placenta, and nasopharyngeal aspirate of the neonate, collected at birth were positive. On day 2 , the neonate developed clinical features of COVID in the form of fever, poor feeding, and hyperbilirubenemia along with elevated inflammatory markers. Antibiotics were started empirically pending cultures. Blood, CSF, and urine cultures were sterile. Baby tested RT-PCR positive for SARS-CoV-2 on two more occasions before testing positive for antibodies and was discharged on day 21 of life.

Conclusion This report highlights a very strong possibility of vertical transmission of COVID-19 from a mildly symptomatic, RT-PCR negative but antibody-positive mother with significant symptomatic, early—onset neonatal infection.
\end{abstract}

Keywords COVID- $19 \cdot$ Neonate $\cdot$ Vertical transmission

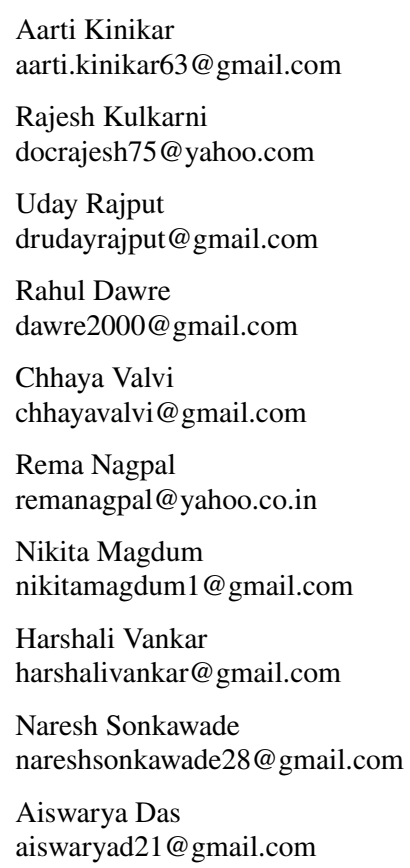

Sagar Vartak

sagarvartak72@gmail.com

Suvarna Joshi

suvarnajoshi@hotmail.com

Santosh Varma

drsantoshgvarma@yahoo.com

Rajesh Karyakarte

karyakarte@hotmail.com

Ramesh Bhosale

drrameshbhosale@yahoo.com

1 Department of Pediatrics, B.J. Government Medical College, J. P. Narayan Road, Pune, India

2 Department of Microbiology, B.J. Government Medical College, J. P. Narayan Road, Pune, India

3 Department of Biochemistry, B.J. Government Medical College, J. P. Narayan Road, Pune, India

4 Department of Obstetrics and Gynecology, B.J. Government Medical College, J. P. Narayan Road, Pune, India 


\section{Introduction}

Small case series of pregnant women with severe acute respiratory syndrome (SARS) or Middle East respiratory syndrome (MERS), did not observe any vertical transmission [1]. There is sparse data about COVID-19 in pregnancy, particularly related to the possibility of vertical transmission [2-4].

This report describes the clinical course and laboratory findings in a neonate born in Pune, India in whom infection with SARS-CoV-2 very likely occurred via vertical transmission. The neonate developed signs and symptoms of COVID-19 along with evidence of significant inflammation on day 2 of life.

\section{Case presentation}

A 24-year-old primigravida was admitted at $38+2$ week gestation with fever and body ache for 1 day. Mother was in active labor. As per the guidelines of the Indian Council of Medical Research (ICMR), she was managed in a COVID isolation facility in the hospital and a nasopharyngeal swab was sent. The baby was delivered by ventouse due to maternal exhaustion.

The delivery was performed in a large, well ventilated delivery room. This was the only delivery conducted on that day and the delivery room was fumigated a few hours before the mother arrived. All healthcare staff involved wore personal protective equipment (PPE) as per hospital guidelines for conducting delivery in a COVID suspect/confirmed mother. N 95 masks, visors, long-sleeved gowns, and sterile gloves were used by all personnel involved in delivering the baby. The mother, who was wearing a surgical mask, was brought in from the opposite end of the room, where resuscitaire was situated. The neonatal team was called half an hour before the baby was born and they donned PPE outside the delivery room. They remained next to the resuscitaire throughout the $10 \mathrm{~min}$ they were inside the delivery room. The baby was placed in a delivery tray with a sterile drape and immediately transferred to the resuscitaire by a pediatrician. Delayed cord clamping or skin to skin contact was not done. The baby did not require any resuscitation at birth and was assigned APGAR scores of six and nine at one and $5 \mathrm{~min}$ of life. No oropharyngeal or nasal suction was done. The birth weight was $3200 \mathrm{~g}$.

The baby was transferred to the separate neonatal room with airborne and contact isolation precautions. The baby was fed with infant formula and did not have contact with any family members. Reverse transcriptase (RT) PCR was performed on nasopharyngeal aspirate (NPA), cord stump, and placenta at birth. All the samples were collected observing strict aseptic precautions to ensure zero contamination. We did not collect any blood samples from the baby on day 1. NPA from baby, cord stump, and placenta (which were collected as per national guidelines at birth) were reported as positive for SARS-CoV2 at $12 \mathrm{~h}$ of life. Mother tested negative for SARS-CoV2 on the first swab (collected on admission) and again on day 5 .

At $38 \mathrm{~h}$ of life, the baby was found to have fever, icterus, and poor feeding. A provisional clinical diagnosis of neonatal sepsis was made and IV antibiotics (Ampicillin plus Gentamicin) were started immediately after collecting blood culture and other tests for neonatal sepsis.CSF was done which revealed five cells (all lymphocytes) with normal protein and sugar. There was no ABO or Rh incompatibility and the Direct Coomb's Test was negative.

Over the next 2 days, the baby continued to have fever spikes, and investigations done showed thrombocytopenia and elevated inflammatory markers (CRP/Procalcitonin/ Ferritin) with elevated d-dimers (Table 1). Antibiotics were changed to Meropenem and Vancomycin and a decision was made to add Lopinavir Ritonavir (as an antiviral drug for SARS-CoV2, extrapolating evidence from use in newborns for HIV) and IVIG because of clinically significant illness with very high inflammatory markers. The chest radiograph, ECG, and 2 D Echo were normal. Antibiotics were discontinued after negative culture reports.

The nasopharyngeal swab of the neonate for SARSCoV-2 RT-PCR, obtained at delivery was positive. RT-PCR repeated on day 5 and day 10 was positive. Maternal serology on postpartum day 2 was negative for antibodies, followed by positive antibodies on repeat testing on postpartum day 10 (day 11 after symptom onset in mother, titers 10.26 COI) and 21 (titers $87.68 \mathrm{COI}$ ). Baby tested negative for antibodies on day 10 but tested positive for antibodies on day 21 (titers 5.25 COI). (Antibodies were done by e CLIA on Cobas e411 Roche using Elecsys Anti SARS-CoV-2) (Fig. 1).

Over the next few days, the baby showed clinical improvement, although the inflammatory markers (serum ferritin and d-dimer) remained abnormal for the next few days (Fig. 2). The day 14 NPA for SARS-CoV2 was negative. The baby was discharged on day 21 of life after establishing lactation and arranging family support for mother and baby.

\section{Discussion}

We report a case of early-onset COVID disease in a newborn who very likely acquired the infection vertically. The transmission occurred either via the transplacental route antenatally close to delivery or intrapartum. There are two cohort 
Table 1 Infant's blood tests

\begin{tabular}{|c|c|c|c|c|c|c|}
\hline Time & Day 2 & Day 4 & Day 6 & Day 10 & Day 15 & Day 21 \\
\hline Hemoglobin (11-18 g/dl) & 17.8 & 16.2 & 15.5 & 13.5 & 12.9 & 12.3 \\
\hline Hematocrit & 52 & 47 & 49 & 39 & 35 & 34 \\
\hline Total Leucocyte count $\left(4-11 \times 10^{3} / \mu \mathrm{l}\right)$ & 16.2 & 10.6 & 11 & 10 & 11 & 10 \\
\hline NLR (1-3) & 1.1 & 0.7 & 0.6 & 0.6 & 0.7 & 0.6 \\
\hline Platelets $\left(150-500 \times 10^{3} / \mu \mathrm{l}\right)$ & 268 & 151 & 123 & 255 & 350 & 320 \\
\hline Serum sodium (125-145 mEq/l) & 136 & 129 & - & 134 & 138.2 & - \\
\hline Serum potassium $(3.5-5.5 \mathrm{mEq} / \mathrm{l})$ & 4.28 & 4.2 & - & 5 & 4.8 & - \\
\hline Serum urea $(15-40 \mathrm{mg} / \mathrm{dl})$ & 34 & 38 & - & 20 & - & - \\
\hline Serum creatinine $(0.7-1.5 \mathrm{mg} / \mathrm{dl})$ & 0.5 & 0.4 & - & 0.3 & - & - \\
\hline AST (8-40 IU/l) & 22 & 63 & - & 79 & 39 & - \\
\hline ALT (1-40 IU/1) & 44 & 28 & - & 17 & 22 & - \\
\hline Alkaline phosphatase (64-306 IU/l) & 150 & 145 & - & 304 & 296 & - \\
\hline Total bilirubin & 8.3 & 10.3 & 6.4 & 2.3 & 1.59 & 1.0 \\
\hline Direct bilirubin & 1.2 & 2.1 & 1.6 & 1.0 & 0.35 & 0.2 \\
\hline Serum ferritin $(7-84$ ng/ml) & 774 & 8711 & 15,091 & 6243 & 164 & 80 \\
\hline CK-MB (0-24 U/1) & 20 & - & & - & - & - \\
\hline Serum amylase $(0-80 \mathrm{IU} / \mathrm{l})$ & 28 & - & 34 & - & - & - \\
\hline Serum lipase (0-160 IU/l) & 31 & - & 29 & - & - & - \\
\hline INR $(0.75-1.5)$ & 1.45 & - & 1.3 & - & - & - \\
\hline Activated prothrombin time (up to $60 \mathrm{~s}$ ) & 48 & 4 & 42 & - & - & - \\
\hline D-dimer $(0.1-0.5 \mathrm{mg} / \mathrm{l})$ & 1.4 & 5.7 & 8.9 & 4.46 & 2.1 & 0.6 \\
\hline Procalcitonin $(0-0.5 \mathrm{mg} / \mathrm{ml})$ & & & 0.2 & 0.11 & - & - \\
\hline C-reactive protein $(0-0.6 \mathrm{mg} / \mathrm{dl})$ & Negative & 4.4 & 6.2 & 1.4 & 0.5 & - \\
\hline Blood culture & No growth & & & & & \\
\hline CSF analysis & $\begin{array}{l}5 \text { cells } \\
\text { All Lymphocytes, } \\
\text { sugar-100, pro- } \\
\text { teins-30 }\end{array}$ & & & & & \\
\hline CSF culture & No growth & & & & & \\
\hline Urine routine and microscopy & Normal & & & & & \\
\hline Urine culture & No growth & & & & & \\
\hline
\end{tabular}

$N L R$ neutrophil:lymphocyte ratio, $C R P$ C-reactive protein, $C K-M B$ creatine kinase-myocardial bound, INR international normalized ratio

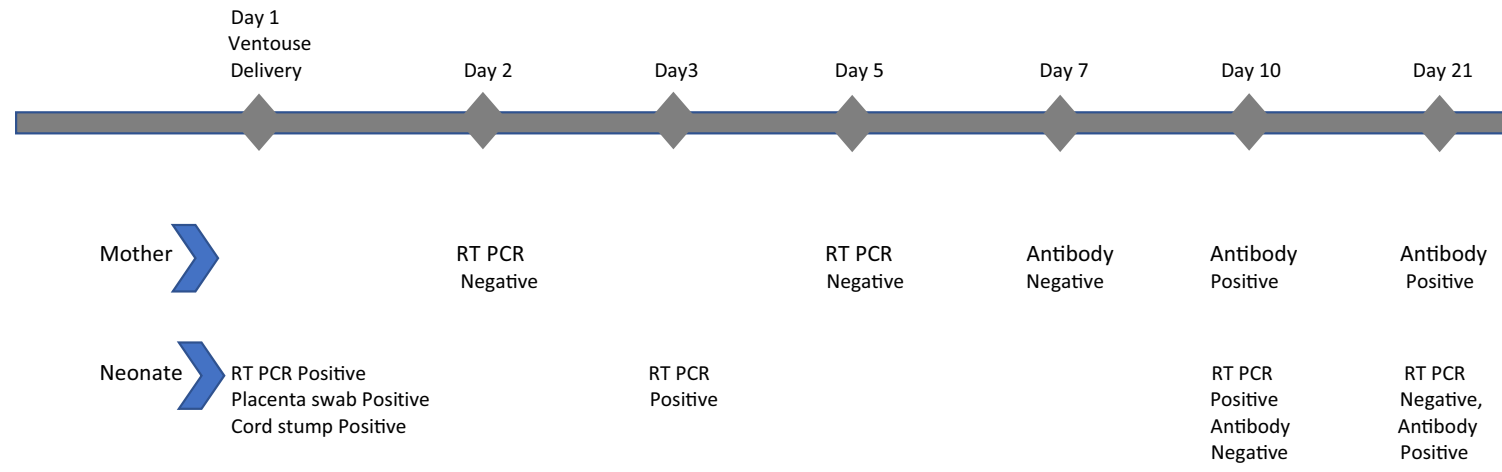

Fig. 1 Timeline depicting RT-PCR and serology results evolution in mother and neonate. RT-PCR real-time polymerase chain reaction 


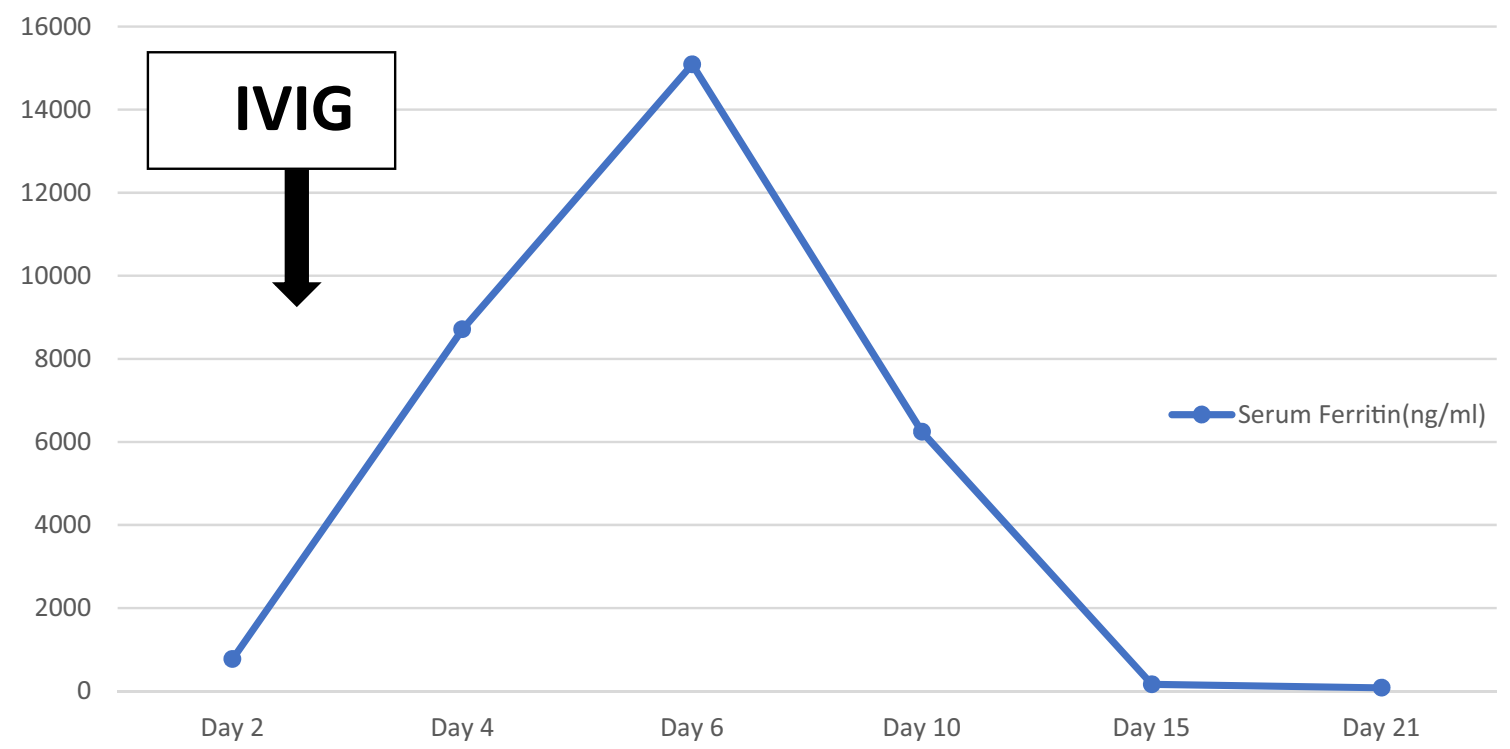

Fig. 2 Line graph showing trend of serum ferritin

studies, where several neonates tested positive at birth, with suspected vertical transmission. There are two case reports of preterm neonates with SARS-CoV2 infection acquired transplacentally $[2,4-6]$.

Prior studies have failed to demonstrate the maternal-fetal transmission of SARS-CoV-2, including negative testing in amniotic fluid, umbilical cord blood, vaginal swabs, and breast milk. Two neonates with positive RT-PCR testing as early as $30 \mathrm{~h}$ after delivery have been reported; however, these cases lacked sufficient clinical data or precise information regarding isolation methods, and perinatal transmission could not be ruled out $[7,8]$.

In a case series of 33 neonates born to mothers with COVID-19, the clinical symptoms were mild with favorable outcome in most patients [9]. Three of the neonates developed confirmed COVID-19, including one with critical illness likely unrelated to SARS-CoV-2.

In our case, the mother was suspected to have COVID19 based on her symptoms. Her NPAs on day of admission and day 5 tested negative for SARS-CoV2; however, she tested positive for antibodies on day 10 after delivery. It is known that the RT-PCR test may be false negative in up to one-third cases. This indicates an "aborted" infection before few days of delivery that did not localize to the respiratory tract but which probably resulted in a viremia leading to infection in the baby. On day 10 , the baby tested negative for antibodies. This could be because the immature neonatal immune system may not mount an antibody response. However, at discharge on day 21 , the baby tested positive for antibodies. To the best of our knowledge, there is only one case report, where possible perinatal transmission occurred and the newborn tested positive at $16 \mathrm{~h}$ of life [10]. In that case, the mother developed a severe respiratory illness due to COVID, and the newborn required mechanical ventilation briefly. In our case, the mother only had a fever for 1 day before delivery, while the baby developed clinical sepsis on day 2 .

Postnatal transmission is extremely unlikely in our case. The mother was wearing a mask, no aerosol-generating procedure was performed on the mother and mother, and the baby was separated immediately after birth with no subsequent contact until day 11. In addition, the distance between the mother and the resuscitaire makes droplet transmission of SARS-CoV-2 from the mother very unlikely. Surface or droplet transmission from an infected healthcare worker was unlikely as all staff in the delivery room were asymptomatic for 2 weeks following the delivery and all staff in contact with the infected neonate during the admission were wearing $\mathrm{N} 95$ masks and using contact precautions. The baby was fed formula milk thus ruling out transmission via breast milk. A major finding in our case is the positive testing on RT-PCR of the placenta, cord stump, and neonatal nasopharyngeal swab collected at the time of birth. In addition, not only was the baby actively shedding the virus at birth but also the baby developed symptomatic COVID infection with raised inflammatory markers on day 2 of life. Therefore, we strongly believe vertical transmission is highly likely in our case.

The current guidelines do not take into account the possibility of antenatal transmission. There is a need to include this possibility of antenatal transmission; even from mildly symptomatic mothers in future guidelines. An international registry for emergent pathogens and pregnancy has already been initiated [11]. Such a robust surveillance system will 
help identify more cases of vertical transmission of COVID19 and help generate data for future guidelines.

\section{Compliance with ethical standards}

Conflict of interest The author(s) declare that they have no competing interests.

\section{References}

1. de Wit E, van Doremalen N, Falzarano D, Munster VJ. SARS and MERS: recent insights into emerging coronaviruses. Nat Rev Microbiol. 2016;14:523-34. https://doi.org/10.1038/nrmic ro.2016.81.

2. Vivanti AJ, Vauloup-Fellous C, Prevot S, et al. Transplacental transmission of SARS-CoV-2 infection. Nat Commun. 2020;11:3572. https://doi.org/10.1038/s41467-020-17436-6.

3. Baud D, Greub G, Favre G, et al. Second-trimester miscarriage in a pregnant woman with SARS-CoV-2 infection. JAMA. 2020;323:2198-200. https://doi.org/10.1001/jama.2020.7233.

4. Sisman J, Jaleel M, Moreno W, Rajaram V, et al. Intrauterine transmission of SARS-CoV-2 infection in a preterm infant. Pediatr Infect Dis J. 2020. https://doi.org/10.1097/inf.000000000000281 5 .
5. Knight M, Bunch K, Vousden N, et al. Characteristics and outcomes of pregnant women admitted to hospital with confirmed SARS-CoV-2 infection in UK: national population based cohort study. BMJ. 2020;369:m2107. https://doi.org/10.1136/bmj.m2107

6. Martínez-Perez O, Vouga M, Cruz Melguizo S, et al. Association between mode of delivery among pregnant women with COVID19 and maternal and neonatal outcomes in Spain. JAMA. 2020. https://doi.org/10.1001/jama.2020.10125.

7. Zhu H, Wang L, Fang C, et al. Clinical analysis of 10 neonates born to mothers with 2019-nCoV pneumonia. Transl Pediatr. 2020;9:51-60. https://doi.org/10.21037/tp.2020.02.06.

8. Dashraath P, Wong JLJ, Lim MXK, et al. Coronavirus disease 2019 (COVID-19) pandemic and pregnancy. Am J Obstet Gynecol. 2020;222:521-31. https://doi.org/10.1016/j. ajog.2020.03.021.

9. Zeng L, Xia S, Yuan W, et al. Neonatal early-onset infection with SARS-CoV-2 in 33 neonates born to mothers with COVID-19 in Wuhan, China. JAMA Pediatr. 2020;174:722-5. https://doi. org/10.1001/jamapediatrics.2020.0878.

10. Alzamora MC, Paredes T, Caceres D, Webb CM, Valdez LM, La Rosa M. Severe COVID-19 during Pregnancy and Possible Vertical Transmission. Am J Perinatol. 2020;37:861-5. https:// doi.org/10.1055/s-0040-1710050.

11. Panchaud A, Favre G, Pomar L, et al. An international registry for emergent pathogens and pregnancy. Lancet. 2020;395:1483-4. https://doi.org/10.1016/S0140-6736(20)30981-8. 